\title{
Aujeszky's disease virus: opportunities and challenges
}

\author{
Federico A. ZUCKERMANN \\ Department of Veterinary Pathobiology, University of Illinois, \\ 2001 South Lincoln Ave. Urbana, Illinois 61801, USA
}

\begin{abstract}
Since its description in 1902, Aujeszky's disease (AD) has become one of the most thoroughly examined viral diseases of swine. The causative agent, Aujeszky's disease virus (ADV), is a neurotropic alphaherpesvirus that produces fatal encephalitis in newborn pigs and a milder syndrome in older animals. In several instances this virus has been used as a test case to examine novel vaccine concepts in swine, including the honor of being the first genetically modified vaccine used in the field. Furthermore, the examination of the immune response to infection or vaccination with this virus has revealed important information about the function of the porcine immune system, including evidence on the existence of a dichotomy between the humoral and cellular immune response in swine. This review presents a summary of research where ADV has been a valuable tool for the development of novel vaccines and has provided information to better understand the immune response of swine to infectious agents.
\end{abstract}

\section{Aujeszky's disease virus / immunity / vaccine / T cells / pig}

Résumé - Virus de la maladie d'Aujeszky : perspectives et défis. Depuis sa description en 1902, la maladie d'Aujeszky est devenue l'une des maladies virales du porc les plus minutieusement étudiées. L'agent pathogène responsable de la maladie, le virus de la maladie d'Aujeszky, est un alphaherpesvirus neurotrope qui provoque des encéphalites fatales chez le porc nouveau-né, et un syndrome plus modéré chez les animaux plus âgés. À plusieurs reprises, ce virus a été utilisé expérimentalement pour l'étude de nouveaux concepts vaccinaux chez le porc, et a eu l'honneur d'être le premier vaccin génétiquement modifié utilisé sur le terrain. De plus, l'examen de la réponse immunitaire à l'infection ou à la vaccination par ce virus a révélé des informations importantes concernant le fonctionnement du système immunitaire porcin. En particulier, des preuves de l'existence d'une dichotomie entre les réponses immunitaires humorale et cellulaire chez le porc ont été mises en évidence. Cet article de synthèse résume la recherche pour laquelle ADV a été un outil précieux pour le développement de nouveaux vaccins, et a apporté des informations pour une meilleure compréhension de la réponse immunitaire du porc aux agents infectieux.

virus de la maladie d'Aujeszky / immunité / vaccin / cellules T / porc 


\section{Table of contents}

1. Introduction

2. Immunity to inactivated and modified live Aujeszky's disease virus vaccines ................ 122

3. Dichotomy between the humoral and cellular immune responses of swine to ADV ......... 125

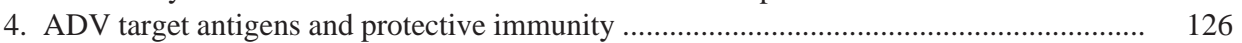

5. ADV and novel vaccine design ..................................................................... 126

6. Immunity to ADV and pig T cell biology ......................................................... 127

7. Immunity to ADV as a benchmark for the porcine immune response ............................ 127

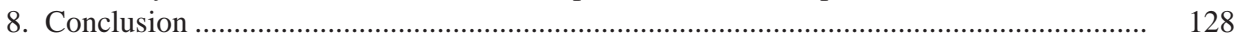

\section{INTRODUCTION}

Aujeszky's disease virus (ADV) causes a natural infection in swine similar to that of herpes simplex virus (HSV) in man. ADV is a neuroinvasive virus with a wide host range that excludes only primates. The severity of the clinical outcome resulting from the infection with this virus is determined by the age and immunological status of the animal, as well as the virulence and dose of exposure of the virus. Young pigs from nonimmune sows are extremely susceptible to this virus, with a high mortality rate approaching $100 \%$ during the first two weeks of age and decreasing to $50 \%$ in the third and fourth weeks of age. The disease in older pigs is not lethal and is characterized by severe depression, anorexia, pyrexia, ataxia, and respiratory distress. In pregnant sows the virus can produce abortion [2]. This virus became more prevalent in the pig population as a result of the intensification of pork production systems. Due to similarity to HSV, worldwide distribution of and economic importance, ADV has been the subject of numerous studies designed to examine its pathogenesis, molecular properties and immunobiology $[31,32,58]$. The vast accumulation of knowledge concerning the biology of this virus makes it particularly well suited as a tool to study the biology of the porcine immune system and to test novel concepts in vaccine design. This review will emphasize the immunological events occurring during the infection or vaccination with ADV, as well as examples where ADV has been used to test the effectiveness of novel vaccine concepts including DNA vaccination, and the use of recombinant heterologous vaccine vectors such as poxvirus and adenovirus.

\section{IMMUNITY TO INACTIVATED AND MODIFIED LIVE AUJESZKY'S DISEASE VIRUS VACCINES}

The efficacy of vaccination against ADV has been examined extensively under a variety of experimental and field conditions. The types of vaccines that have been examined include live virus, inactivated virus, and subunit vaccines. In general, ADV modified live virus (MLV) vaccines are very effective at inducing protective immunity under experimental conditions (reviewed in $[19,32,58])$. Similarly, under field conditions, intensive regional vaccination programs have been very effective at controlling the spread of the disease between herds and reducing the incidence of infection [42-44]. The effectiveness of a ADV vaccine is dependent on the immunization program, strain of the vaccine virus, level of exposure to the virus and the level of maternally derived antibodies at the time of vaccination [4, 11, 14, 50, 52, 55]. For example double vaccination of young pigs with a MLV vaccine has been shown to be more effective than single vaccination at reducing the incidence of infection in swine populations at high risk of infection with field virus [45]. Although the precise mechanism responsible for this effect has not been 
directly examined, there are two likely explanations. The first possibility relates to the role of passive immunity interfering with the development of active immunity. The lower levels of maternally derived ADVspecific antibodies by the time of the second vaccination, usually two to four weeks later, would allow for the priming of the immune system and development of active immunity. The second possible explanation relates to the fact that even in young pigs with no passive ADV immunity, two vaccinations stimulate a stronger humoral and cellular immune response than one vaccination $[4,51,61]$. The route of immunization is also important. Counter to intuition, intranasal vaccination does not appear to confer a higher level of protective immunity than parenteral vaccination against ADV $[1,23]$. Indeed on a head to head comparison, parenteral vaccination is better able to induce protective immunity, as measured by weight gain, than intranasal immunization [55]. This effect is most likely due to the fact that although ADV infection starts as a respiratory infection, the virus quickly spreads systemically and attacks the central nervous system and the reproductive system in pregnant sows. Without adequate systemic immunity the animal will be susceptible to pervasive spread of the virus to the target organs and produce the consequent pathological effects. An additional important issue that needs consideration in immunity to ADV is the ability of the vaccine virus to prevent or reduce the establishment of latent infection by the wild-type virus. Osorio et al. [39] demonstrated an inverse correlation between the extent of precolonization of the trigeminal ganglia attained by the attenuated vaccine virus and the level of establishment of latency by superinfecting wild-type ADV. That is, the more the vaccine virus is able to colonize the ganglia the less the challenge virus is able to do so. In addition, intramuscular immunization has been shown to be more effective than intranasal immunization at inducing immunity capable of preventing the establishment of latent infection by wildtype ADV [55].

Experimentally, protective immunity can be induced by inoculation with both live and inactivated ADV vaccines [12, 56, 61]. However, although both vaccines protect immunized animals from death and/or severe illness due to wild-type ADV challenge, the clinical response has measurable differences [53]. Challenge of vaccinated pigs results in a reduction in the rate of growth (weight gain), and even weight loss, depending on the severity of the challenge and level of protective immunity conferred by the vaccine [50, 52]. Weight changes observed within seven days after ADV challenge has been shown to be a sensitive, reproducible and statistically sound parameter that allows the quantification of the level of protective immunity conferred by different ADV vaccines [46]. Use of this measurement has demonstrated that indeed inactivated vaccines are less effective than live vaccines at inducing protective immunity $[11,50,51,61]$. Immunization with both inactivated and MLV virus vaccines induce a strong humoral immune response. In both cases this response is characterized by the presence of high titers of virus-neutralizing antibodies [11, 21, 61]. However, since the inactivated vaccines are less able to induce protective immunity, it becomes apparent that a high titer of virus-neutralizing antibodies is not necessarily associated with the presence of protective immunity $[20,27,51,52])$. Because of this observation, it seems plausible that the level of cellular immunity would be higher in animals immunized with the MLV vaccine than in those receiving an inactivated vaccine. In theory, a strong cellular immune response should influence in a positive fashion the clinical outcome following challenge with virulent ADV. Until recently the cellular immune response to an inactivated ADV vaccine had not been examined. We have now shown that indeed the cellular immune response to an inactivated ADV vaccines is lower than that induced by a MLV vaccine 

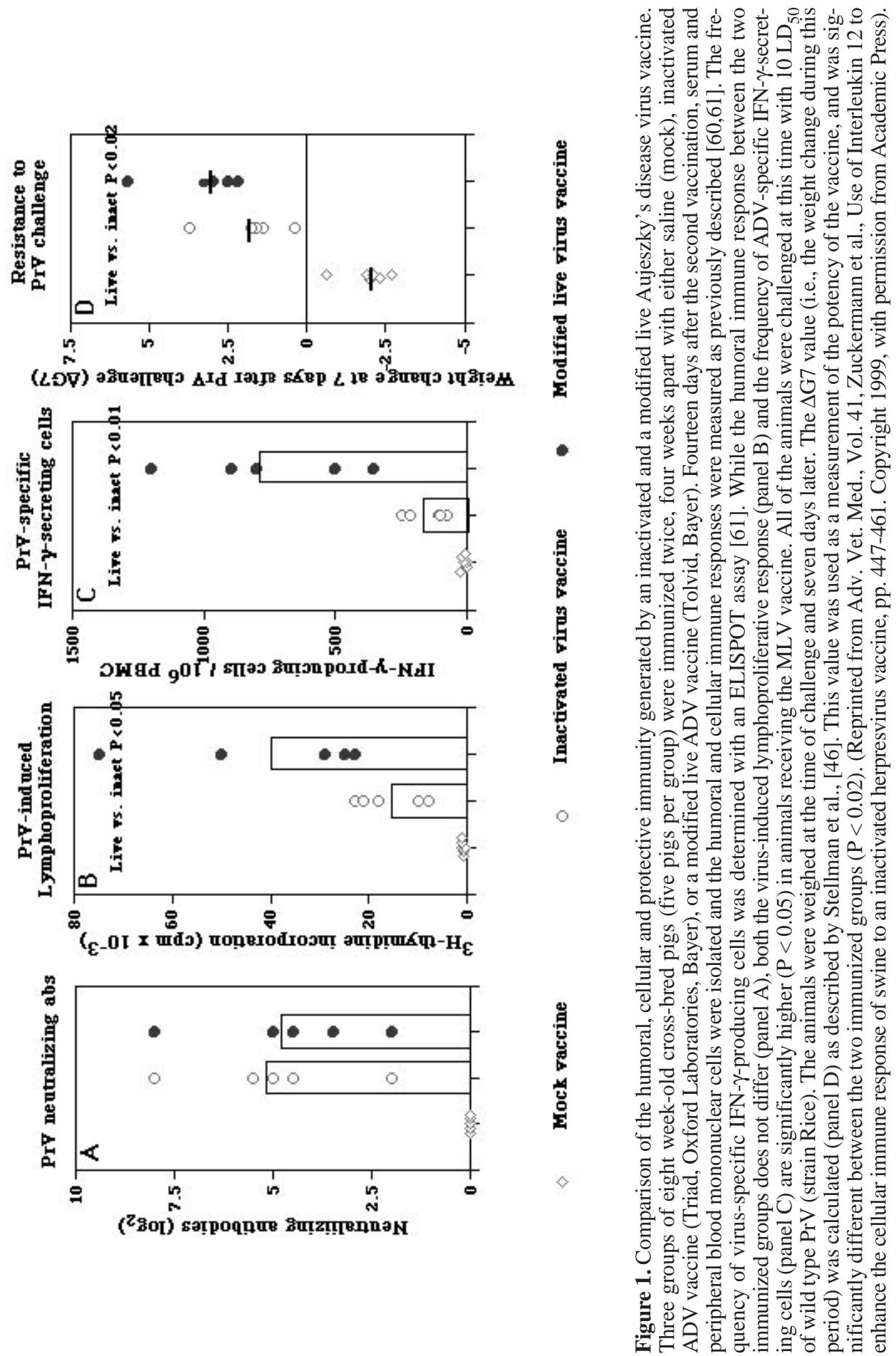
(see [61, 62] and Fig. 1). It is known that immunization with a MLV vaccine generates a robust cytotoxic $\mathrm{T}$ lymphocyte response [59], as well as a strong lymphoproliferative $[21,60]$ and IFN- $\gamma$ response [61]. The virus-specific cytotoxic lymphocyte response is mediated by CD8 single positive (SP) lymphocytes, while the lymphoproliferative and IFN- $\gamma$ responses are mediated predominantly by CD4/CD8 double positive (DP) T lymphocytes and to a lesser extent by CD4 single positive (SP) $\mathrm{T}$ cells $[21,47,59,60,62]$. Although direct evidence of the relative importance of cellmediated immunity in mediating protection against ADV infection is unavailable, as discussed below, recent evidence indicates that at least a positive correlation does exist.

\section{DICHOTOMY BETWEEN THE HUMORAL AND CELLULAR IMMUNE RESPONSES OF SWINE TO ADV}

Studies by Kimman et al. demonstrated that a second challenge with virulent ADV induced a secondary virus-specific cellular immune response in the absence of a boost of anti-viral humoral immunity [10, 21]. This observation is important because it revealed for the first time the existence of a dichotomy between the humoral and cellular branches of the porcine immune system. In a different approach, Zuckermann et al. have obtained further evidence of the existence of this dichotomy by directly comparing the humoral and cellular immune responses of pigs to two rounds of immunization with a live versus an inactivated ADV vaccine [61]. These studies clearly revealed that while a commercial inactivated vaccine is capable of inducing an equal titer of virus neutralizing antibodies as a MLV vaccine (Fig. 1A), the former is much less capable of stimulating the generation of virus-specific interferon (IFN)- $\gamma$-secreting cells (Fig. 1C; [61]). These results demonstrate that in the pig a strong humoral immune response can occur independently of a strong cellular immune response, and these two responses are therefore independently regulated. Furthermore, and just as important, these vaccination experiments clearly show that protection from disease correlates with the presence of a strong cell mediated immune response but not with the titer of virus neutralizing antibodies. More striking evidence of the existence of this dichotomy was observed by immunizing pigs with inactivated ADV vaccine, but given without an adjuvant. In this situation, the titer of virus neutralizing antibodies induced by the unadjuvanted inactivated virus was substantial, and not much different from that induced by the same inactivated virus mixed with an adjuvant. In contrast, the frequency of virus-specific IFN- $\gamma$-producing cells produced in response to immunization with the unadjuvanted inactivated virus was almost zero, while the response to the adjuvanted inactivated vaccine was considerable (Zuckermann et al., unpublished observations). The observation of a dichotomy between the humoral and cellular immune responses of pigs to an infectious agent, is akin to the observations made on the dichotomy between the humoral and cellular immune responses of humans to intracellular infections [9]. The paradigm of the Th1 and Th2 type regulation of immunity has been proposed as an explanation of the mechanism behind this immunological dichotomy [41a, 48]. The same paradigm can be reasonably put forth to explain the phenomenon described in the porcine vaccination studies described above. This postulate is further supported by the fact that the administration of recombinant IL-12 at the time of vaccination can significantly enhance the intensity of the cellular immune response of a pig to an inactivated vaccine [61]. The ability of IL-12 to drive the immune response of mice to microbial antigens, including ADV, into a Th1 type response is well-recognized [30a, 38, 40, 41a, 48]. The fact that IL-12 can have a sim- 
ilar effect in the pig argues in favor of the existence of similar mechanisms of regulation of cellular immunity.

\section{ADV TARGET ANTIGENS AND PROTECTIVE IMMUNITY}

Many studies on swine immunity to ADV have focused on the identification of ADV antigens targeted by the immune system. Initially, Ben-Porat and collaborators recognized the importance of the virus envelope glycoproteins in the induction of immunity resulting from natural virus infection. Antibodies against glycoprotein $\mathrm{C}(\mathrm{gC})$ were found to account for the majority of the virus neutralizing activity in convalescent pig serum [3]. This glycoprotein was also found to be a major target for cytotoxic $\left(\mathrm{CD}^{+}\right)$[59] and helper $\left(\mathrm{CD}^{+}\right) \mathrm{T}$ cells (Zuckermann et al., unpublished observations) isolated from ADV immune pigs. More recently two epitopes in the $\mathrm{gC}$ protein recognized by helper $\mathrm{T}$ cells have been identified [36]. It is thus clear that $\mathrm{gC}$ is a major target of both humoral and cellular immunity resulting from either infection or vaccination with ADV. Antibodies specific for another major envelope glycoprotein, $\mathrm{gD}$, are also able to neutralize the infectivity of ADV, an event independent of complement [13]. Similar to $\mathrm{gC}, \mathrm{gD}$ is also a target for T-cells (Zuckermann, unpublished observations). Although the role of $\mathrm{gD}$ in immunity to ADV has not been thoroughly examined, researchers had suspected that $\mathrm{gD}$ could be as important as $\mathrm{gC}$ in the development of protective immunity. Indeed, immunization of pigs with ADV gC or gD have been shown to protect pigs from ADV challenge $[17,26,29]$. Similarly, immunization with a subunit vaccine based on the essential major envelope glycoprotein, $\mathrm{gB}$, was shown to induce protective immunity in pigs [35]. Likewise, more recent studies have verified the ability of purified ADV glycoproteins to induce protective immunity $[18,49]$. Thus, utilization of one or more of these three ADV envelope glycoproteins for the development and testing of novel vaccines for pigs is warranted.

\section{ADV AND NOVEL VACCINE DESIGN}

Although vaccines against ADV are highly effective, the ability to readily measure protective immunity against this disease in pigs, and the availability of the genes coding for $\mathrm{gC}, \mathrm{gD}$ and $\mathrm{gB}$ has made $\mathrm{ADV}$ an ideal model to test the effectiveness of new vaccine concepts in a large animal. Vaccines based on heterologous viruses expressing cloned ADV glycoprotein genes have been successfully developed and tested for efficacy. These include recombinant swinepox virus, vaccinia virus and replication deficient adenoviruses ([6, 37]; Zuckermann and Tripathy, unpublished observations). One situation in which this type of vaccine might have a practical use in the field would be to circumvent the inhibitory activity of colostral antibodies on the immune response to a conventional vaccine. Both recombinant vaccinia viruses and adenoviruses expressing gD have been shown to successfully accomplish this task [7, 8, 24, 34]. Perhaps the most promising vaccine technology currently being tested is the administration of naked DNA encoding for antigens known to have the potential to induce protective immunity. So far, the administration of plasmids capable of expressing either $\mathrm{gC}$ or $\mathrm{gD}$ have been shown to induce immunity and in several cases protection in pigs against Aujeszky's disease $[15,16,33,54]$. A critical challenge remaining for this technology is the demonstration that the effectiveness of DNA vaccination can be made to emulate the level of protective immunity induced by conventional MLV vaccines. Among the possibilities being explored to enhance the potency of DNA vaccines is the use of "genetic adjuvants". These immunological enhancers consist of secondary plasmids coding for porcine cytokines known to enhance 
immunity and are co-administrated with the primary antigen-expressing plasmids. Alternatively, it might also be feasible to include within the primary plasmid $\mathrm{CpG}$ motifs which have been shown to enhance immunity to DNA vaccines in mice [22]. However, since these motifs are species-specific, this will require first the identification of $\mathrm{CpG}$ motifs that are active in the pig. The use of genes coding for the porcine cytokines as DNA vaccine adjuvants is also starting to be examined. For example, GM-CSF has now been shown to enhance the development of protective immunity to ADV DNA vaccines based on $\mathrm{gB}$ and $\mathrm{gD}$ [41b]. However, whether or not the level of immunity achieved is comparable to that induced by a MLV vaccine remains to be examined. Similarly, Martin et al. [28], examined the modulatory effect of plasmids encoding for porcine IFN- $\gamma$ and IL-10 on the intensity of the IFN- $\gamma$ response to the genetic immunization with a plasmid encoding for ADV gC. Surprisingly, contrary to the expected result based on murine literature, and despite the fact that IL-10 has been shown to suppress the IFN- $\gamma$ response of porcine $\mathrm{T}$ cell in vitro (Martin and Zuckermann, unpublished observations), IL-10 was shown to enhance the IFN- $\gamma$ response to the genetic immunization with $\mathrm{gC}$. Although further studies are in progress to clarify and confirm this result, this observation does indicate that the assumption that observations made in one species are applicable to another is not justified. Similarly, although the issue of the route of DNA administration has been addressed in some of the published studies on porcine DNA vaccination, the optimal route and method of delivery of nucleic acid for the immunization of pigs remains to be determined.

\section{IMMUNITY TO ADV AND PIG T CELL BIOLOGY}

A great deal of the knowledge that has been acquired on the biology of pig T cells has been performed by examining the immune response of swine to viruses, in particular ADV [25]. Studies on ADV immunity provided key evidence for the demonstration that CD4/CD8 double positive cells are comprised predominantly of memory $\mathrm{T}$ cells and have a helper function $[36,60]$. The ADV model was also used to examine the kinetics of the immune response in porcine lymphoid tissues [5]. Infection with ADV was also utilized as a test case to demonstrate the utility of a tissue chamber model to examine in vivo the inflammatory/immune responses and cytokine production in the pig [57]. More recently we have performed detailed phenotypic analyses of the leukocytes attracted to the cerebrospinal fluid of pigs during a ADVinduced encephalitis. This approach has allowed us to demonstrate that CD4/CD8 double positive cells are selectively recruited to this fluid during this inflammatory response (Husmann and Zuckermann, unpublished results). The trafficking behavior of porcine CD4/CD8 DP T cells is what we had predicted based on the notion that this lymphocyte subset is comprised predominantly of memory T cells [60].

\section{IMMUNITY TO ADV \\ AS A BENCHMARK \\ FOR THE PORCINE IMMUNE RESPONSE}

Although the knowledge that we have acquired on the immune response to $\mathrm{ADV}$ is incomplete, it is sufficient to be used as a benchmark to evaluate the quality and intensity of the cellular immunity to other microbes. This comparison has proven valuable in the case of PRRS virus. By performing such comparison, we have concluded that the cellular immune response to either infection or vaccination with PRRS virus is delayed and rather weak [30b]. We are hopeful that this and other ongoing studies will lead to the development of better vaccines against PRRS virus. This approach 
could be similarly applied to other swine pathogens to assess the strength of the immune response and the development of effective vaccines.

\section{CONCLUSION}

Because of the familiarity that many scientists have with ADV and availability of reagents, it seems likely that this virus will continue to be the model of choice for understanding the mechanisms that determine the quality and intensity of the cellular immune response of pigs to an infectious agent. Although much remains to be learned about this process, it is safe to say that the increasing availability of reagents and cloned porcine cytokine genes will speed-up the acquisition of knowledge on the porcine immune system. A great opportunity that is ripe for exploitation is the use of recombinant porcine cytokines to examine the regulation of the cellular immune response of swine to infectious agents. As described above, the poor cellular immune response induced by an inactivated ADV vaccine has been used to demonstrate that IL-12 can enhance the intensity of IFN- $\gamma$ response to immunization with an ADV vaccine [61]. These experiments suggest that IL-12 must play a central role in the generation of cellular immunity in pigs. The effect of this and other cytokines on regulating the intensity of the cellular immune response both in vivo and in vitro remains to be fully explored, specially given the possibility of obtaining results that differ from the current dogma [28]. We expect that these types of studies will yield valuable insights and guidance for the rational development of the next generation of vaccine adjuvants for pigs, which could be termed "designer adjuvants". Designer adjuvants will allow us to modulate and achieve the desired type of vaccine-induced immunity that will provide the type of immune response best suited to mediate protective immunity against a given type of microbe. Our understanding of the mechanism(s) of adjuvant action in pigs is meager, and is for the most part derived from work in other species, mostly mice. This type of information is essential for the rational design of vaccines for pigs. If we understand the rules that regulate the immune response of swine, we could then apply this knowledge in a systematic and rational way to formulate and predict the behavior of a given vaccine. The ultimate goal of a vaccine is to induce sterile immunity. We know that this is an attainable goal since this type of immunity is seen in convalescent pigs after an infection with ADV [21]. Whether this level of immunity is simply the result of the intense viral replication and generation of significant antigenic mass, or is due to some innate property of the wildtype virus that is lost during attenuation is unknown. What is known is that reduction of virulence is accompanied by a reduction in the level of protective immunity conferred by the vaccine [20]. Clarification of this issue is likely to give an insight into how to develop the most potent vaccine possible. As evidenced by previous studies, ADV will continue to be of great value not only as a tool to unravel the mysteries of the porcine immune system, but also as a model against which new vaccine concepts can be tested. Given all of the information described above, it is reasonable to expect that our understanding of the biology of the pig's immune system will continue to expand. This knowledge will be helpful in the development of effective vaccines against current and emerging diseases of swine.

\section{ACKNOWLEDGMENTS}

The author acknowledges Drs. Stephen Martin, Joan K. Lunney and William Meier for reviewing the manuscript. This work was supported in part by grants from the USDA-NRI program (96-02328) and by the Illinois Department of Agriculture. 


\section{REFERENCES}

[1] Arellano P.E., Morrison R.B., Molitor T.W., Thawley D.G., High- and low-challenge exposure doses used to compare intranasal and intramuscular administration of pseudorabies virus vaccine in passively immune pigs, J. Am. Vet. Med. Assoc. 200 (1992) 685-691.

[2] Baskerville A., Aujeszky's disease: recent advances and current problems, N. Z. Vet. J. 29 (1981) 183-189.

[3] Ben-Porat T., DeMarchi J.M., Lomniczi B., Kaplan A.S., Role of glycoproteins of pseudorabies virus in eliciting neutralizing antibodies, Virology 154 (1986) 325-331.

[4] Bouma A., De Jong M.C., Kimman T.G., The influence of maternal immunity on the transmission of pseudorabies virus and on the effectiveness of vaccination, Vaccine 15 (1997) 287-294.

[5] Bouma A., Zwart R.J., De Bruin M.G., De Jong M.C., Kimman T.G., Bianchi A.T., Immunohistological characterization of the local cellular response directed against pseudorabies virus in pigs, Vet. Microbiol. 58 (1997) 145-151.

[6] Brockmeier S.L., Lager K.M., Tartaglia J., Riviere M., Paoletti E., Mengeling W.L.,Vaccination of pigs against pseudorabies with highly attenuated vaccinia (NYVAC) recombinant viruses, Vet. Microbiol. 38 (1993) 41-58.

[7] Brockmeier S.L., Lager K.M., Mengeling W.L., Successful pseudorabies vaccination in maternally immune piglets using recombinant vaccinia virus vaccines, Res. Vet. Sci. 62 (1997) 281-287.

[8] Brockmeier S.L., Lager K.M., Mengeling W.L., Vaccination with recombinant vaccinia virus vaccines expressing glycoprotein genes of pseudorabies virus in the presence of maternal immunity, Vet. Microbiol. 58 (1997) 93-99.

[9] Bullock W.E., Anergy and infection, Adv. Intern. Med. 21 (1976) 149-173.

[10] De Bruin M.G., De Visser Y.E., Kimman T.G., Bianchi A.T., Time course of the porcine cellular and humoral immune responses in vivo against pseudorabies virus after inoculation and challenge: significance of in vitro antigenic restimulation, Vet. Immunol. Immunopathol. 65(1998) 75-87.

[11] de Leeuw P.W., van Oirschot J.T., Vaccines against Aujeszky's disease: evaluation of their efficacy under standardized laboratory conditions, Vet. Q. 7 (1985) 191-197.

[12] Donaldson J.T., Wardly R.C., Martin S., Harkness J.W., Influence of vaccination of Aujeszky's disease virus and disease transmission, Vet. Record. 115 (1987) 121-126.

[13] Eloit M., Fargeaud D., L'Haridon R., Toma B., Identification of the pseudorabies virus glycoprotein gp50 as a major target of neutralizing antibodies, Arch Virol. 99 (1988) 45-51.
[14] Firkins L.D., Weigel R.M., Biehl L.G., Hahn E.C., Field trial to evaluate the immunogenicity of pseudorabies virus vaccines with deletions for glycoproteins G and E, Am. J. Vet. Res. 58 (1997) 976-984.

[15] Gerdts V., Jons A., Makoschey B., Visser N., Mettenleiter T.C., Protection of pigs against Aujeszky's disease by DNA vaccination, J. Gen. Virol. 78 (1997) 2139-2145.

[16] Haagmans B.L., van Rooij E.M., Dubelaar M., Kimman T.G., Horzinek M.C., Schijns V.E., Bianchi A.T., Vaccination of pigs against pseudorabies virus with plasmid DNA encoding glycoprotein D, Vaccine 17 (1999) 1264-1271.

[17] Katayama S., Okada N., Yoshiki K., Okabe T., Shimizu Y., Protective effect of glycoprotein gCrich antigen against pseudorabies virus, J. Vet. Med. Sci. 59 (1997) 657-660.

[18] Katayama S., Yoshiki K., Okada N., Kokubu T., Shimizu Y., Efficacy of a mixed glycoprotein vaccine against pseudorabies in pregnant sows. J. Vet. Med. Sci. 60 (1998) 23-28.

[19] Kimman T.G., Comparative efficacy of three doses of the genetically engineered Aujeszky's disease virus vaccine strain 783 in pigs with maternal antibodies, Vaccine 10 (1992) 363-365.

[20] Kimman T.G., De Wind N., De Bruin T., de Visser Y., Voermans J., Inactivation of glycoprotein $\mathrm{gE}$ and thymidine kinase or the US3encoded protein kinase synergistically decreases in vivo replication of pseudorabies virus and the induction of protective immunity, Virol. 205 (1994) 511-518.

[21] Kimman T.G., De Bruin T.M.G., Voermans J.J.M., Peeters B.P.H., Bianchi A.T.T., Development of antigen specificity of the lymphoproliferation response of pigs to pseudorabies virus: dichotomy between secondary B-and T-cells responses. Immunol. 86 (1995) 372-378.

[22] Krieg A.M., Yi A.K., Schorr J., Davis H.L., The role of CpG dinucleotides in 1998 DNA vaccines, Trends Microbiol. 6 (1998) 23-27.

[23] Labarque G.G., Nauwynck H.J., Maes D.G., Pensaert M.B., Protection of fattening pigs against challenge with Aujeszky's disease virus after a successive intranasal/intramuscular vaccination., Vet. Q. 21 (1999) 104-107.

[24] Le Potier M.F., Monteil M., Houdayer C., Eloit M., Study of the delivery of the gD gene of pseudorabies virus to one-day-old piglets by adenovirus or plasmid DNA as ways to by-pass the inhibition of immune response by colostral antibodies. Vet. Microbiol. 55 (1997) 75-80.

[25] Lunney J.K., Saalmuller A., Pauly T., Boyd P., Hyatt S., Strom D., Martin S., Zuckermann F.A., Cellular Immune Responses Controlling Infectious Diseases, in: M.E. Tumbleson and L.B. Schook. (Eds.), Advances in Swine in Biomedical Research, Plenum Press, p. 307.

[26] Marchioli C.C., Yancey R.J. Jr., Petrovskis E.A., Timmins J.G., Post L.E., Evaluation of 
pseudorabies virus glycoprotein gp50 as a vaccine for Aujeszky's disease in mice and swine: expression by vaccinia virus and Chinese hamster ovary cells, J. Virol. 61 (1987) 3977-3981.

[27] Martin S., Wardley R.C., Donaldson A.I., Functional antibody responses in pigs vaccinated with live and inactivated Aujeszky's disease virus, Res. Vet. Sci. 41 (1986) 331-335.

[28] Martin S., Russell P.F., Jaqua P.M., Grimm S., Lowery D., Strom D., Zuckermann F.A., Effects of cytokines upon the immune response of swine to Aujeszky's disease virus, 3rd International Symposium on PRRS and Aujeszky's disease, Ploufragan, France, 21-24 June 1999, Vet. Res. 31 (2000) 133-134

[29] Matsuda A., Okada N., Katayama S., Okabe T., Sasaki N., Characterization of protective viral glycoproteins for pseudorabies virus infection, J. Vet. Med. Sci. 53 (1991) 737-741.

[30a]McKnight A.J., Zimmer G.J., Fogelman I., Wolf S.F., Abbas A.K., Effects of IL-12 on helper T cell-dependent immune responses in vivo, $\mathrm{J}$. Immunol. 152 (1994) 2172-2181.

[30b]Meier W., Wheeler J., Husmann R.J., Osorio F., Zuckermann F.A., Characteristics of the immune response of pigs to PRRS virus, 3rd International Symposium on PRRS and Aujeszky's disease, Ploufragan, France, 21-24 June 1999, Vet. Res. 31 (2000) 41 .

[31] Mettenleiter T.C. , Molecular biology of pseudorabies (Aujeszky's disease) virus, Comp. Immun. Microbiol. Infect. Dis. 14 (1991) 151158.

[32] Mettenleiter T.C., Immunobiology of pseudorabies (Aujeszky's disease), Vet. Immunol. Immunopathol. 54 (1996) 221-229.

[33] Monteil M., Le Potier M.F., Guillotin J., Cariolet R., Houdayer C., Eloit M., Genetic immunization of seronegative one-day-old piglets against pseudorabies induces neutralizing antibodies but not protection and is ineffective in piglets from immune dams, Vet. Res. 27 (1996) 443-452.

[34] Monteil M., Le Potier M.F., Cariolet R., Houdayer C., Eloit M., Effective priming of neonates born to immune dams against the immunogenic pseudorabies virus glycoprotein $\mathrm{gD}$ by replication-incompetent adenovirus-mediated gene transfer at birth, J. Gen. Virol. 78 (1997) 3303-3310.

[35] Nakamura T., Ihara T., Nunoya T., Kuwahara H., Ishihama A., Ueda S., Role of pseudorabies virus glycoprotein II in protection from lethal infection, Vet. Microbiol. 36 (1993) 83-88.

[36] Ober B.T., Summerfield A., Mattlinger C., Wiesmuller K.H., Jung G., Pfaff E., Saalmuller A., Rziha H.J., Vaccine-induced, pseudorabies virus-specific, extrathymic $\mathrm{CD} 4^{+} \mathrm{CD}^{+}$memory T-helper cells in swine, J Virol. 72 (1998) 48664870

[37] Riviere M., Tartaglia J., Perkus M.E., Norton E.K., Bongermino C.M., Lacoste F., Duret C.,
Desmettre P., Paoletti E., Protection of mice and swine from pseudorabies virus conferred by vaccinia virus-based recombinants, J. Virol. 66 (1992) 3424-3429.

[38] Romani L., Puccetti P., Bistoni F., Interleukin12 in infectious diseases, Clin. Microbiol. Rev. 10 (1997) 611-636.

[39] Schang L.M., Kutish G.F., Osorio F.A., Correlation between precolonization of trigeminal ganglia by attenuated strains of pseudorabies virus and resistance to wild-type virus latency, J. Virol. 68 (1994) 8470-8476.

[40] Schijns V.E., Haagmans B.L., M.C. Horzinek, IL-12 stimulates an antiviral type-1 cytokine response but lacks adjuvant activity in IFN- $\gamma$ receptor-deficient mice, J. Immunol. 155 (1995) 2525-2532.

[41a]Scott P., Trinchieri G., IL-12 as an adjuvant for cell-mediated immunity, Semin. Immunol. 9 (1997) 285-291.

[41b]Somasundaram C., Takamatsu H., Lefèvre F., Charley B., Enhanced protective response and immuno-adjuvant effects of porcine GM-CSF on DNA vaccination of pigs against Aujeszky's disease virus, 3rd International Symposium on PRRS and Aujeszky's disease, Ploufragan, France, 2124 June 1999, Vet. Res. 31 (2000) 134-135.

[42] Stegeman J.A., Kimman T.G., Van Oirschot J.T., Tielen M.J., Hunneman W.A., Spread of Aujeszky's disease virus within pig herds in an intensively vaccinated region, Vet. Rec. 134 (1994) 327-330.

[43] Stegeman J.A., Tielen M.J., Kimman T.G., Van Oirschot J.T., Hunneman W.A., Berndsen F.W., Intensive regional vaccination with a gI-deleted vaccine markedly reduces pseudorabies virus infections, Vaccine 12 (1994) 527-531.

[44] Stegeman A., Van Oirschot J.T., Kimman T.G., Tielen M.J., Hunneman W.A., Berndsen F.W., Reduction of the prevalence of pseudorabies virus-infected breeding pigs by use of intensive regional vaccination, Am. J. Vet. Res. 55 (1994) 1381-1385.

[45] Stegeman A., Van Nes A., de Jong M.C., Bolder F.W., Assessment of the effectiveness of vaccination against pseudorabies in finishing pigs. Am.J. Vet. Res. 56 (1995) 573-578.

[46] Stellman C., Vannier P., Chappuis G., Brunn A., Dauvergne M., Fargeaud D., Bugand M., Colson $\mathrm{X}$., The potency testing of pseudorabies vaccines in pigs: a proposal for a quantitative criterion and a minimum requirement, J. Biol. Stand. 17 (1989) 17-27.

[47] Summerfield A., Rziha H.J., Saalmuller A., Functional characterization of porcine $\mathrm{CD} 4^{+} \mathrm{CD} 8^{+}$ extrathymic T lymphocytes, Cell Immunol. 168 (1996) 291-298

[48] Trinchieri G., Interleukin-12: A proinflammatory cytokine with immunoregulatory functions that bridge innate resistance and antigen-specific adap- 
tive immunity, Annu. Rev. Immunol. 13 (1995) 251-276.

[49] Vanderpooten A., Goddeeris B., De Roose P., Hendrickx L., Biront P., Desmettre P., Evaluation of parenteral vaccination methods with glycoproteins against Aujeszky's disease in pigs, Vet. Microbiol. 55 (1997) 81-86.

[50] Vannier P., Experimental infection of fattening pigs with pseudorabies (Aujeszky's disease) virus: efficacy of attenuated live- and inactivated-virus vaccines in pigs with or without passive immunity, Am. J. Vet. Res. 46 (1985) 1498-1502.

[51] Vannier P., Hutet E., Bourgueil E., Cariolet R., Level of virulent virus excreted by infected pigs previously vaccinated with different glycoprotein deleted Aujeszky's disease vaccines, Vet. Microbiol. 29 (1991) 213-223.

[52] Van Oirschot J.T., deLeeuw P.W., Intranasal vaccination of pigs against Aujeszky's disease. 4. Comparison with one or two doses of an inactivated vaccine in pigs with moderate maternal antibody titres, Vet. Microbiol. 10 (1985) 401408 .

[53] van Oirschot J.T., Kaashoek M.J., Rijsewijk F.A., Stegeman J.A., The use of marker vaccines in eradication of herpesviruses, J. Biotechnol. 44 (1996) 75-81.

[54] van Rooij E.M., Haagmans B.L., de Visser Y.E., de Bruin M.G., Boersma W., Bianchi A.T., Effect of vaccination route and composition of DNA vaccine on the induction of protective immunity against pseudorabies infection in pigs, Vet. Immunol. Immunopathol. 66 (1998) 113-117.

[55] Vilnis A., Sussman M.D., Thacker B.J., Senn M., Maes R.K., Vaccine genotype and route of administration affect pseudorabies field virus latency load after challenge, Vet. Microbiol. 62 (1998) 81-96.

[56] Wardley R.C., Thomsen D.R., Berlinski P.J., Post L.E., Meyer A.L., Petrovskis E.A., Chester S.T., Immune response in pigs to Aujeszky's disease viruses defective in glycoprotein $\mathrm{g} 1$ or $\mathrm{gX}$, Res. Vet. Sci. 50 (1991) 178-183.

[57] Wattrang E., Wallgren P., Fuxler L., Lindersson M., Fossum C., Tissue chambers - a useful model for in vivo studies of cytokine production in the pig. Vet. Immunol. Immunopathol. 56 (1997) 133-139.

[58] Wittmann G., Spread and control of Aujeszky's disease (AD). Comp. Immunol. Microbiol. Infect. Dis. 14 (1991) 165-173.

[59] Zuckermann F.A., Zsak L., Mettenleiter T.C., Ben-Porat T., Pseudorabies virus glycoprotein gIII is a major target antigen for murine and swine virus-specific cytotoxic T lymphocytes, J. Virol. 64 (1990) 802-812.

[60] Zuckermann F.A., Husmann R.J., Functional and phenotypic analysis of porcine peripheral blood CD4/CD8 double-positive T cells. Immunology 87 (1996) 500-509.

[61] Zuckermann F.A., Husmann R.J., Schwartz R., Brandt J., Mateu de Antonio E., Martin S., Interleukin-12 enhances the virus-specific interferon gamma response of pigs to an inactivated pseudorabies virus vaccine, Vet. Immunol. Immunopathol. 63 (1998) 57-67.

[62] Zuckermann F.A., Martin S., Husmann R.J., Brandt J., Use of interleukin 12 to enhance the cellular immune response of swine to an inactivated herpesvirus vaccine, Adv. Vet. Med. 41 (1999) 447-461. 